CLINICAL STUDY

\title{
A hypoechoic pattern of the thyroid at ultrasound does not indicate autoimmune thyroid diseases in patients with morbid obesity
}

\author{
Mario Rotondi, Carlo Cappelli ${ }^{1}$, Paola Leporati, Spyridon Chytiris, Francesca Zerbini, Rodolfo Fonte, \\ Flavia Magri, Maurizio Castellano ${ }^{1}$ and Luca Chiovato \\ Unit of Internal Medicine and Endocrinology, Fondazione Salvatore Maugeri I.R.C.C.S., ISPESL Laboratory for Endocrine Disruptors and \\ Chair of Endocrinology, University of Pavia, Via S. Maugeri 10, I-27100 Pavia, Italy and ${ }^{1}$ Internal Medicine and Endocrinology Unit, \\ Department of Medical and Surgical Sciences, University of Brescia, I-25100 Brescia, Italy \\ (Correspondence should be addressed to L Chiovato; Email: luca.chiovato@fsm.it)
}

\begin{abstract}
Objective: Thyroid ultrasound (US) scan is a valuable tool for diagnosing thyroid diseases. In autoimmune thyroid disease (AITD), an hypoechoic pattern of the thyroid at US is related to circulating thyroid antibodies (Abs). The aim of this study was to evaluate the diagnostic accuracy of thyroid US for the detection of AITD in patients with morbid obesity.

Design: Thyroid US scans showing an hypoechoic pattern of the thyroid were collected from 105 morbid obese patients (body mass index (BMI) $>40 \mathrm{~kg} / \mathrm{m}^{2}$ ) and 105 non-obese patients $\left(\mathrm{BMI} \leq 30 \mathrm{~kg} / \mathrm{m}^{2}\right)$.

Results: A thyroid hypoechoic pattern at US was consistent with clinical/biochemical features of AITD in $90 / 105(85.7 \%)$ non-obese patients and in $22 / 105(20.9 \%)$ morbid-obese patients $(P<0.0001)$. By performing a complete thyroid work-up, including clinical examination, thyroid morphology, serum hormones, and auto-Ab measurements, the discrepancy between the US pattern and the results of the thyroid $\mathrm{Ab}$ tests was justified in 6/15 non-obese patients, and only in 1/83 morbid obese patients. Thus, an unexplained hypoechoic pattern of the thyroid at US, defined as negative tests for thyroid $\mathrm{Ab}$ and absence of justifying thyroid disturbances, was found in 2/105 (1.9\%) non-obese patients and in $68 / 105(64.8 \%)$ morbid obese patients $(P<0.0001)$.

Conclusions: Our results suggest that i) morbid obesity may affect thyroid morphology, and ii) an hypoechoic pattern of the thyroid at US, a well-established parameter for diagnosing AITD, has a poor diagnostic accuracy when patients with morbid obesity are taken into account.
\end{abstract}

European Journal of Endocrinology 163 105-109

\section{Introduction}

Over the last decade, ultrasound (US) scans proved to be a valuable tool for the diagnostic work-up of thyroid diseases (1-8). Besides estimation of thyroid volume and identification of non-palpable thyroid nodules (9), US scans are able to characterize the echographic structure of thyroid tissue (10). The typical normal thyroid parenchyma has a peculiar high echo density due to the follicle structure (9). The interface between thyroid cells and the colloid exhibits an elevated acoustic impedance, causing high-frequency acoustic waves to be reflected back to the probe. In autoimmune thyroid diseases (AITDs), however, both lymphocytic infiltration and disruption of normal tissue architecture cause a reduction in thyroid echogenicity $(1,4,6,10,11)$. Thyroid hypoechogenicity is currently viewed as an early sign of thyroid autoimmunity, which may be present even when the thyroid disorder is not suspected from a clinical point of view $(4,6,7,12,13)$. Rapid improvements in US equipment and the use of standardized computerized algorithms have permitted an objective and quantitative measurement of tissue echogenicity in thyroid diseases (11-13), as well as in other pathological conditions $(14,15)$. Using a subjective measure of thyroid echogenicity, previous studies demonstrated that in patients with thyroid autoimmune diseases, the presence of circulating thyroid antibodies (Abs) as well as the development of hypothyroidism was closely correlated with the degree of thyroid hypoechogenicity $(1,5,11,12,16)$.

It is a common observation that a significant proportion of patients with morbid obesity display slightly increased serum levels of TSH (17). The elevation of serum TSH, also within the normal range, is associated with an increase in the occurrence of obesity (18). However, there is still considerable disagreement as to the physiopathological mechanism 
responsible for this phenomenon and the clinical significance of this hyperthyrotropinemia (17). A recent study from our group questioned whether an elevated serum TSH alone provides sufficient evidence for a diagnosis of subclinical hypothyroidism in patients with morbid obesity (19). Little has been reported on the morphology of the thyroid gland in adults with morbid obesity $(20,21)$. A recent study, performed in obese children, showed for the first time that obesity is associated with structural changes in thyroid morphology, as assessed by US, which are unrelated to thyroid autoimmunity (22). The aim of the current study was to evaluate the diagnostic accuracy of thyroid US for the detection of thyroid autoimmune diseases in adult patients with morbid obesity. For this purpose, patients with an hypoechoic pattern of the thyroid at US were enrolled and stratified according to their body weight status.

\section{Patients and methods}

\section{Subjects}

Obese patients and controls were recruited by searching the computerized database of thyroid US performed at the Unit of Internal Medicine and Endocrinology of the Fondazione Salvatore Maugeri from January 2007 to July 2009. Search criteria were an hypoechoic pattern of the thyroid at US and the patient's body mass index (BMI). A total of 105 consecutive patients with morbid obesity (BMI>40) were collected.

The control group was constituted by normo-weight and/or slightly overweight $\left(\mathrm{BMI} \leq 30 \mathrm{~kg} / \mathrm{m}^{2}\right)$ patients who had performed a thyroid US scan, which revealed a hypoechoic pattern of the gland.

Starting from January 2007, consecutive non-obese patients were recruited until the same number of morbidly obese patients was reached. In the control group, $76(72.4 \%)$ patients were normo-weight $\left(\mathrm{BMI} \leq 25 \mathrm{~kg} / \mathrm{m}^{2}\right)$, and $29(27.6 \%)$ patients were slightly overweight (BMI $25-30 \mathrm{~kg} / \mathrm{m}^{2}$ ).

A two-step search procedure was used as follows: i) all the scans performed in patients with a BMI $>40 \mathrm{~kg} / \mathrm{m}^{2}$ showing the presence of thyroid hypoechogenicity were collected. When more than one scan for a single patient was available, only the first one was considered. A total of 105 scans were collected; ii) starting from the date when the first obese patient was enrolled, 105 consecutive US scans performed in patients with $\mathrm{BMI} \leq 30 \mathrm{~kg} / \mathrm{m}^{2}$ showing the presence of thyroid hypoechogenicity were collected. The last collected scan was performed 45 days later, and no patient had performed more than one scan. The procedure could by no means discriminate any clinical characteristic other than name, sex, and BMI of the patient, together with the name of the US operator. A total of 210 scans showing an hypoechoic pattern of the thyroid at US were collected. The clinical data of the corresponding patients were obtained from computerized and written hospital notes. These included age, free thyroxine $\left(\mathrm{FT}_{4}\right)$, free tri-iodothyronine $\left(\mathrm{FT}_{3}\right)$, TSH, thyroglobulin $\mathrm{Ab}$ ( Tg $A b)$, thyroid peroxidase $A b$ (TPO Ab), TSH receptor Ab (TR Ab), and a detailed drug history.

BMI was calculated as the weight $(\mathrm{kg})$ measured to the nearest $\mathrm{kg}$, divided by the square of height determined to the nearest $\mathrm{cm}(\mathrm{m})$. Isolated hyperthyrotropinemia (a condition frequently encountered in patients with morbid obesity) (20) was defined as a raised serum level of $\mathrm{TSH}$ with normal $\mathrm{FT}_{4}$ and $\mathrm{FT}_{3}$ levels, in the absence of circulating thyroid $\mathrm{Ab}$.

All subjects gave their informed consent to participate in the study, which was performed in accordance with the guidelines of the Declaration of Helsinki.

\section{Thyroid US}

Thyroid USs were performed using a real-time US device (Sonosite 180 plus) equipped with a linear transducer operating at 7.5 MHz for morphologic study (L38 linear probe). The volume of the thyroid, as assessed by measuring the three largest perpendicular diameters, and the US pattern of the thyroid parenchyma are recorded for each scan. In order to minimize the operator variability in assessing thyroid echogenicity, only those scans performed by the same operator $(\mathrm{S} \mathrm{C})$, who was well trained and had a 5-year experience in thyroid imaging, were selected. According to previous studies, echogenicity was evaluated in both thyroid lobes and in the surrounding neck muscles on the transverse section $(12,16)$. The isthmus was excluded to avoid the interference of reflecting echoes from the tracheal cartilage. Hypoechogenicity was ascertained by comparison of the echo distribution in the thyroid parenchyma with respect to the surrounding neck muscles, and only those scans showing mild to severe generalized hypoechogenicity were selected $(12,16)$.

\section{Serum assays}

Serum concentrations of $\mathrm{FT}_{4}$ (normal range: 8.0-19.0 pg/ml), $\mathrm{FT}_{3}$ (normal range: $1.8-4.2 \mathrm{pg} / \mathrm{ml}$ ), and TSH (third generation TSH assay; normal range: 0.4-4.0 mIU/l) were measured using immunochemiluminiscent assays by an automated analyser (Immulite 2000, DPC Cirrus, Los Angeles, CA, USA) employing commercial kits (Diagnostic Products Corporation, Los Angeles, CA, USA). The serum concentrations of $\mathrm{Tg} \mathrm{Ab}$ (normal range: $<60 \mathrm{U} / \mathrm{ml}$ ), TPO Ab (normal range: $<60 \mathrm{U} / \mathrm{ml}$ ), and TR Ab (normal range: $<1 \mathrm{U} / \mathrm{ml}$ ) were measured using immunochemiluminiscent assays employing commercial kits (Brahms, Hennigsdorf, Germany). 


\section{Statistical analysis}

Statistical analysis was performed using the SPSS software (SPSS, Inc., Evanston, IL, USA). Betweengroup comparisons were performed by Student's $t$-test for unpaired data and by the Mann-Whitney $U$ test according to a normal or a non-parametric distribution of the variable tested. Frequencies among groups were compared by $\chi^{2}$ test with Fisher's correction, when appropriate. A $P$ value $<0.05$ was considered statistically significant.

\section{Results}

The clinical and biochemical data of the patients with a hypoechoic pattern of the thyroid at US, subdivided according to their body weight phenotype (non-obese versus morbidly obese), are reported in Table 1 . The two groups of patients displayed significant differences for all parameters except for age and thyroid volume. The percentage of patients in whom thyroid US hypoechogenicity was consistent with the biochemical features of AITD (positive thyroid Ab tests) were significantly different $(P<0.0001)$ between the two groups. By means of US, 90 out of $105(85.7 \%)$ patients in the non-obese group were correctly identified as having AITD. Of these, 77 out of $90(85.5 \%)$ patients had a clinical diagnosis of chronic autoimmune thyroiditis, and 13 out of $90(14.5 \%)$ patients were affected by Graves' disease. In the obese group, there were only 22 out of 105 (20.9\%) patients showing a correspondence between a hypoechoic pattern of the thyroid at US and positive tests for thyroid Ab. Of these a clinical diagnosis of chronic autoimmune thyroiditis was made in 21 out of $22(95.5 \%)$ patients and Graves' disease in 1 out of 22 $(4.5 \%)$ patients. Overall, there were 15 out of 105 patients in the non-obese group and 83 out of 105 patients in the obese group who showed a hypoechoic pattern of the thyroid at US not accompanied by positivity for any humoral immune marker of AITD. Possible causes explaining the occurrence of a hypoechoic pattern of the thyroid at US in the absence

Table 1 Clinical and biochemical characteristics of patients with a hypoechoic pattern of the thyroid at ultrasound, subdivided according to their body weight status.

\begin{tabular}{llll}
\hline & \multicolumn{2}{l}{ Thyroid hypoechoic pattern } & \\
\cline { 2 - 3 } & $\begin{array}{l}\text { Non-obese } \\
\text { patients }\end{array}$ & $\begin{array}{l}\text { Morbidly obese } \\
\text { patients }\end{array}$ & \\
& $\boldsymbol{P}$ value \\
\hline Number of cases & 105 & 105 & \\
Age (years) & $48.4 \pm 14.1$ & $46.2 \pm 12.4$ & 0.391 \\
Sex (M/F) & $7 / 98$ & $34 / 71$ & $<\mathbf{0 . 0 0 0 1}$ \\
BMl $\left(\mathrm{kg} / \mathrm{m}^{2}\right)$ & $\mathbf{2 3 . 9} \pm \mathbf{3 . 1}$ & $\mathbf{4 4 . 2} \pm \mathbf{6 . 2}$ & $<\mathbf{0 . 0 0 0 1}$ \\
Thyroid volume (ml) & $15.9 \pm 11.1$ & $16.2 \pm 14.6$ & 0.903 \\
Thyroid $\mathrm{Ab}^{\mathrm{a}}(\%)$ & $\mathbf{9 0 / 1 0 5}(\mathbf{8 5 . 7 \% )}$ & $\mathbf{2 2 / 1 0 5}(\mathbf{2 0 . 9} \%)$ & $<\mathbf{0 . 0 0 0 1}$ \\
\hline
\end{tabular}

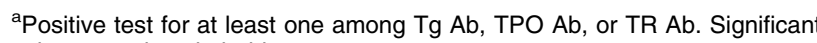
values are given in bold.
Table 2 Thyroid condition found in non-obese and morbidly obese patients showing a thyroid hypoechoic pattern at ultrasound (US) and negative tests for thyroid antibody $(\mathrm{Ab})$.

\begin{tabular}{lcc}
\hline & $\begin{array}{c}\text { Non-obese } \\
\text { patients }\end{array}$ & $\begin{array}{c}\text { Morbidly } \\
\text { obese patients }\end{array}$ \\
\hline $\begin{array}{l}\text { Number of cases } \\
\text { Atrophic thyroiditis }\end{array}$ & $15 / 105$ & $83 / 105$ \\
$\begin{array}{l}\text { Subacute thyroiditis } \\
\text { Graves' disease in remission } \\
\quad \text { after thionamides }\end{array}$ & 1 & 1 \\
$\begin{array}{l}\text { Amiodarone-induced } \\
\quad \text { hypothyroidism }\end{array}$ & 1 & - \\
$\begin{array}{l}\text { Amiodarone-induced type II } \\
\text { thyrotoxicosis }\end{array}$ & 1 & - \\
$\begin{array}{l}\text { Non-toxic multinodular goiter } \\
\text { Toxic multinodular goiter }\end{array}$ & 6 & - \\
$\begin{array}{l}\text { Isolated hyperthyrotropinemia } \\
\text { Lack of detectable thyroid }\end{array}$ & 1 & 3 \\
$\quad$ abnormality & - & - \\
\hline
\end{tabular}

aDefined as a raised serum TSH with normal $\mathrm{FT}_{4}$ and $\mathrm{FT}_{3}$ levels in the absence of circulating thyroid Ab.

${ }^{b}$ Patients in whom a complete thyroid work-up including clinical examination, circulating hormones, and auto-Ab measurements did not provide evidence for thyroid disease.

of a positive test for thyroid $\mathrm{Ab}$ were researched. As shown in Table 2, in 6 out of 15 non-obese patients, the discrepancy between the US pattern and the results of the thyroid $\mathrm{Ab}$ tests was justified by the following conditions: amiodarone-induced hypothyroidism in two cases; amiodarone-induced type II thyrotoxicosis in one patient; atrophic thyroiditis in one patient; subacute thyroiditis in one patient; and Graves' disease in remission after medical treatment with disappearance of thyroid $\mathrm{Ab}$ in one patient. By contrast, in only 1 out of 83 morbidly obese patients showing a discrepancy between the US pattern and the results for circulating thyroid Ab, could the hypoechoic pattern could be explained by the presence of atrophic thyroiditis. Other clinical conditions not potentially related to the hypoechoic pattern of the thyroid at US were nontoxic multinodular goiter in six patients and toxic multinodular goiter in one case among non-obese patients. In the group of patients with morbid obesity, three patients had non-toxic multinodular goiter, and 11 patients had an isolated hyperthyrotropinemia. Thus, in 2 out of 105 (1.9\%) non-obese patients and in 68 out of $105(64.8 \%)$ morbidly obese patients, a hypoechoic pattern of the thyroid was found in the absence of any thyroid abnormality as assessed by a complete thyroid work-up, including clinical examination, thyroid morphology, hormones, and auto-Ab measurements $(P<0.00001)$.

\section{Discussion}

This study shows that the finding of a thyroid hypoechoic pattern at US has a different clinical meaning when observed in non-obese patients as 
compared with those with morbid obesity. In line with previous evidence, we report that a thyroid hypoechoic pattern was strongly suggestive for the presence of AITD, as assessed by positive thyroid Ab tests and/or clinical data, but only in non-obese patients. A correspondence between the US hypoechoic pattern and the biochemical evidence of AITD was found in $85.7 \%$ of the non-obese patients. On the other hand, patients with morbid obesity displayed as little as a $20.9 \%$ concordance rate between thyroid morphology at US and humoral or clinical evidence of thyroid autoimmunity. Thyroid volumes were similar between morbidly obese patients and controls. Ayturk et al. in a specifically designed study reported that euthyroid patients with metabolic syndrome have significantly higher mean thyroid volume and nodule prevalence as compared with euthyroid controls (23). This apparent discrepancy can be solved by considering that our patients had a wide spectrum of thyroid disease, thus preventing conclusions drawn on thyroid volume. Indeed, the current study was specifically designed to include only patients with a hypoechoic pattern, thus allowing us to compare the underlying thyroid conditions in US-matched patients stratified according to a different body weight status. The results would support the concept that thyroid US, a well-established tool for diagnosing AITD $(1,4-6)$, may be less effective when patients with morbid obesity are taken into account. A considerable percentage (10.5\%) of patients with morbid obesity had isolated hyperthyrotropinemia (a laboratory picture which was not observed in non-obese patients). Isolated hyperthyrotropinemia is often observed in patients with morbid obesity, but its pathogenesis remains poorly understood $(17,19)$. Recent evidence showing that lack of female gender prevalence, normal $\mathrm{FT}_{3} / \mathrm{FT}_{4}$ ratios, and normalization of serum TSH following weight loss all support the concept that these patients should not be considered as having subclinical hypothyroidism $(19,24-26)$. In agreement with this concept, we recently demonstrated that morbidly obese patients with a raised serum TSH have a significantly lower rate of thyroid $\mathrm{Ab}$ positivity when compared with TSH-matched normo-weight patients (19). These data suggest that autoimmunity is not a major cause of raised serum TSH in morbidly obese patients.

A hypoechoic pattern of the thyroid at US in the absence of any thyroid abnormality, as assessed by a complete thyroid work-up, including clinical examination, thyroid morphology, hormones, and auto- $\mathrm{Ab}$ measurements, is a relatively rare finding in non-obese patients $(1.9 \%)$, while it is observed in the majority of patients with morbid obesity $(64.8 \%)$. These data indicate profound differences as to the clinical meaning of an hypoechoic pattern of the thyroid at US in relation to adiposity. The question of what is the cause of thyroid US findings in the two groups of patients thus arises. It seems clear from our results and others work that thyroid hypoechogenicity is strongly related to AITD in non-obese patients. On the other hand, the cause of thyroid hypoechogenicity in patients with morbid obesity is difficult to understand. The hypothesis that patients with an extreme weight excess may have a tendency to accumulate fat in the thyroid could be an attractive one. Radetti et al., recently reported that a thyroid hypoechoic pattern at US was found in a high proportion of obese children with no evidence of AITD (22). Thyroid cytology performed in some of these children turned out to be normal, showing only colloid drops and thyrocytes with no inflammatory cell suggesting AITD (22). The issue of thyroid repercussions of fat excess remains open as cytology does not represent an appropriate technique for elucidating the histopathological basis of the imaging abnormalities. Histological examination, specifically focused at studying fat accumulation within the thyroid tissue, would be required to firmly demonstrate this hypothesis. Some clinically relevant considerations stem from this study. First, the complex and yet poorly understood repercussions of morbid obesity on the thyroid gland are not limited to thyroid function, but may also affect thyroid morphology as evaluated by US. Only a minority of morbidly obese patients with a hypoechoic pattern of the thyroid at US display humoral signs of autoimmunity. Thus, a thyroid hypoechoic pattern at US has a poor diagnostic accuracy for AITD when patients with morbid obesity are taken into account.

\section{Declaration of interest}

The authors declare that there is no conflict of interest that could be perceived as prejudicing the impartiality of the research reported.

\section{Funding}

This research did not receive any specific grant from any funding agency in the public, commercial, or not-for-profit sector.

\section{References}

1 Marcocci C, Vitti P, Cetani F, Catalano F, Concetti R \& Pinchera A. Thyroid ultrasonography helps to identify patients with diffuse lymphocytic thyroiditis who are prone to develop hypothyroidism. Journal of Clinical Endocrinology and Metabolism 1991 72 209-213.

2 Vitti P, Rago T, Mancusi F, Pallini S, Tonacchera M, Santini F, Chiovato L, Marcocci C \& Pinchera A. Thyroid hypoechogenic pattern at ultrasonography as a tool for predicting recurrence of hyperthyroidism after medical treatment in patients with Graves' disease. Acta Endocrinologica 1992126 128-131.

3 Vitti P, Lampis M, Piga M, Loviselli A, Brogioni S, Rago T, Pinchera A \& Martino E. Diagnostic usefulness of thyroid ultrasonography in atrophic thyroiditis. Journal of Clinical Ultrasound 199422 375-379.

4 Pedersen OM, Aardal NP, Larssen TB, Varhaug JE, Myking O \& Vik-Mo H. The value of ultrasonography in predicting autoimmune thyroid disease. Thyroid 200010 251-259. 
5 Premawardhana LD, Parkes AB, Ammari F, John R, Darke C, Adams H \& Lazarus JH. Postpartum thyroiditis and long-term thyroid status: prognostic influence of thyroid peroxidase antibodies and ultrasound echogenicity. Journal of Clinical Endocrinology and Metabolism 200085 71-75.

6 Rago T, Chiovato L, Grasso L, Pinchera A \& Vitti P. Thyroid ultrasonography as a tool for detecting thyroid autoimmune diseases and predicting thyroid dysfunction in apparently healthy subjects. Journal of Endocrinological Investigation 200124 763-769.

7 Raber W, Gessl A, Nowotny P \& Vierhapper H. Thyroid ultrasound versus antithyroid peroxidase antibody determination: a cohort study of 451 subjects. Thyroid $200212725-731$.

8 Erdoğan MF, Anil C, Cesur M, Başkal N \& Erdoğan G. Color flow Doppler sonography for the etiologic diagnosis of hyperthyroidism. Thyroid 200717 223-228.

9 Hegedus L \& Karstrup S. Ultrasonography in the evaluation of cold thyroid nodules. European Journal of Endocrinology 1998138 30-31.

10 Gutekunst R, Hafermann W, Mansky T \& Scriba PC. Ultrasonography related to clinical and laboratory findings in lymphocytic thyroiditis. Acta Endocrinologica 1989121 129-135.

11 Loy M, Cianchetti ME, Cardia F, Melis A, Boi F \& Mariotti S. Correlation of computerized gray-scale sonographic findings with thyroid function and thyroid autoimmune activity in patients with Hashimoto's thyroiditis. Journal of Clinical Ultrasound 200432 136-140.

12 Schiemann U, Gellner R, Riemann B, Schierbaum G, Menzel J, Domschke W \& Hengst K. Standardized grey scale ultrasonography in Graves' disease: correlation to autoimmune activity. European Journal of Endocrinology 1999141 332-336.

13 Vitti P. Grey scale thyroid ultrasonography in the evaluation of patients with Graves' disease. European Journal of Endocrinology $200014222-24$.

14 Ulrich J \& Voit C. Ultrasound in dermatology. Part II. Ultrasound of regional lymph node basins and subcutaneous tumours. European Journal of Dermatology 200111 73-79.

15 Pedro LM, Fernandes e Fernandes J, Pedro MM, Goncalves I, Dias NV, Fernandes e Fernandes R, Carneiro TF \& Balsinha C. Ultrasonographic risk score of carotid plaques. European Journal of Vascular and Endovascular Surgery 200224 492-498.

16 Mazziotti G, Sorvillo F, Iorio S, Carbone A, Romeo A, Piscopo M, Capuano S, Capuano E, Amato G \& Carella C. Grey-scale analysis allows a quantitative evaluation of thyroid echogenicity in the patients with Hashimoto's thyroiditis. Clinical Endocrinology 2003 $59223-229$.
17 Reinehr T. Obesity and thyroid function. Molecular and Cellular Endocrinology $2010316165-171$.

18 Knudsen N, Laurberg P, Rasmussen LB, Bülow I, Perrild H, Ovesen L \& Jørgensen T. Small differences in thyroid function may be important for body mass index and the occurrence of obesity in the population. Journal of Clinical Endocrinology and Metabolism 200590 4019-4024.

19 Rotondi M, Leporati P, La Manna A, Pirali B, Mondello T, Fonte R, Magri F \& Chiovato L. Raised serum TSH levels in patients with morbid obesity: is it enough to diagnose subclinical hypothyroidism? European Journal of Endocrinology $2009 \mathbf{1 6 0}$ 403-408.

20 Sari R, Balci MK, Altunbas H \& Karayalcin U. The effect of body weight and weight loss on thyroid volume and function in obese women. Clinical Endocrinology $200359258-262$.

21 Wesche MF, Wiersinga WM \& Smits NJ. Lean body mass as a determinant of thyroid size. Clinical Endocrinology $1998 \mathbf{4 8}$ 701-706.

22 Radetti G, Kleon W, Buzi F, Crivellaro C, Pappalardo L, di Iorgi N \& Maghnie M. Thyroid function and structure are affected in childhood obesity. Journal of Clinical Endocrinology and Metabolism 200893 4749-4754.

23 Ayturk S, Gursoy A, Kut A, Anil C, Nar A \& Tutuncu NB. Metabolic syndrome and its components are associated with increased thyroid volume and nodule prevalence in a mild-to-moderate iodine-deficient area. European Journal of Endocrinology $2009161599-605$.

24 Moulin de Moraes CM, Mancini MC, De Melo ME, Figueiredo DA, Villares SM, Rascovski A, Zilberstein B \& Halpern A. Prevalence of subclinical hypothyroidism in a morbidly obese population and improvement after weight loss induced by Roux-en-Y gastric bypass. Obesity Surgery 200515 1287-1291.

25 Chikunguwo S, Brethauer S, Nirujogi V, Pitt T, Udomsawaengsup S, Chand B \& Schauer P. Influence of obesity and surgical weight loss on thyroid hormone levels. Surgery for Obesity and Related Diseases 20073 631-635.

26 Reinehr T, de Sousa G \& Andler W. Hyperthyrotropinemia in obese children is reversible after weight loss and is not related to lipids. Journal of Clinical Endocrinology and Metabolism $2006 \mathbf{9 1}$ 3088-3091.

Received 6 May 2010

Accepted 7 May 2010 